Check for updates

Cite this: Chem. Sci., 2018, 9, 721

Received 5th September 2017

Accepted 6th November 2017

DOI: $10.1039 / \mathrm{c} 7 \mathrm{sc} 03878 \mathrm{j}$

rsc.li/chemical-science

\section{Te-containing carbon dots for fluorescence imaging of superoxide anion in mice during acute strenuous exercise or emotional changes $\dagger$}

\author{
Wei Zhang, * Ruixia Wang, Wei Liu, Xin Wang, Ping Li, ${ }^{*}$ Wen Zhang, Hui Wang \\ and Bo Tang (iD *
}

Acute strenuous exercise and emotional changes are closely related to important aspects of human health. The superoxide anion $\left(\mathrm{O}_{2}{ }^{-}\right)$, as one of the primary reactive oxygen species (ROS), is intimately associated with major diseases. However, there is no relevant in vivo research for directly indicating the link between $\mathrm{O}_{2} \cdot-$ level and acute physical exercise or emotional changes. Hence, we constructed three fluorescent probes for the detection of $\mathrm{O}_{2}{ }^{-}$, including a Te-containing molecular probe and Se- and Te-containing CDs, and evaluated their properties such as selectivity, sensitivity, instantaneity and dynamic response to $\mathrm{O}_{2}{ }^{\cdot-}$. Through performance comparisons, we found that the Te-containing CDs exhibited reversibility, instantaneity and the highest sensitivity (LOD $\sim 8.0 \mathrm{pM}$ ), under guarantees of specific recognition of $\mathrm{O}_{2}{ }^{\cdot-}$, which ensure they are suitable for tracing native level changes in $\mathrm{O}_{2}{ }^{\cdot-}$ within living systems. The probe was applied for monitoring the levels of $\mathrm{O}_{2}{ }^{\cdot-}$ in mice under the state of intense exercise, irritability and mild depression, which led to the levels of $\mathrm{O}_{2} \cdot{ }^{\cdot-}$ significantly increasing compared to the normal condition. Furthermore, we used the Te-containing CDs for real-time and dynamic imaging of $\mathrm{O}_{2}{ }^{\cdot-}$ fluxes in the brain of mild depression mice and witnessed a positive correlation between $\mathrm{O}_{2} \cdot{ }^{-}$levels and depression. This work provides a new strategy for studying the relationship between acute exercise or emotional changes and diseases at the level of ROS.

\section{Introduction}

Strenuous physical exercise and acute emotional changes are closely related to human health. ${ }^{1-6}$ The superoxide anion $\left(\mathrm{O}_{2}{ }^{\cdot-}\right)$, as one of the primary ROS and an important signal molecule, is associated with major diseases. ${ }^{7-9}$ So are the levels of ROS, especially the first produced $\mathrm{O}_{2}{ }^{\cdot-}$, related to the state of acute exercise or emotional alterations? To explore the relationship between $\mathrm{O}_{2}{ }^{\cdot-}$ and the above-mentioned states, the fluorescence imaging method is an ideal approach because of the advantages of being nondestructive and the ability to afford high spatialtemporal resolution. ${ }^{\mathbf{1 0 , 1 1}}$ Given the special properties of $\mathrm{O}_{2}{ }^{\cdot-}$ including inordinate low levels and mutual transformation between ROS in living systems, the fluorescent probes should possess an ultra-high sensitive, reversible and instantaneous response to $\mathrm{O}_{2}{ }^{\cdot-}$. Currently, with the aim to monitor $\mathrm{O}_{2}{ }^{--}$levels in cells and in vivo, many analytical methods have been

College of Chemistry, Chemical Engineering and Materials Science, Collaborative Innovation Center of Functionalized Probes for Chemical Imaging in Universities of Shandong, Key Laboratory of Molecular and Nano Probes, Ministry of Education, Institute of Biomedical Sciences, Shandong Normal University, Jinan 250014, P. R. China.E-mail: tangb@sdnu.edu.cn

$\dagger$ Electronic supplementary information (ESI) available. See DOI: $10.1039 / \mathrm{c} 7 \mathrm{sc} 03878 \mathrm{j}$ developed. ${ }^{\mathbf{1 2 , 1 3}}$ However, limited by sensitivity and reversibility, existing imaging results of $\mathrm{O}_{2}{ }^{-}$in cells and in vivo are basically achieved by external stimuli, which cannot realize real-time analysis of native $\mathrm{O}_{2}{ }^{--}$fluctuation in biological processes. ${ }^{\mathbf{1 4 - 1 7}}$ In our previous work, we developed a two-photon fluorescent probe (TCA) for dynamic and reversible imaging of $\mathrm{O}_{2}{ }^{\cdot-} \cdot{ }^{\mathbf{1 6}}$ Nevertheless, due to the detection limit of TCA being at the nanomolar level, the $\mathrm{O}_{2}{ }^{--}$level was measured under external stimuli. In order to break through the limitation of the sensitivity of existing probes and to achieve detection of the true endogenous $\mathrm{O}_{2}{ }^{--}$level in vivo, we constructed a polymer nanoprobe $\left(\mathrm{PCLA}_{-} \mathrm{O}_{2}{ }^{-}\right.$) based on chemiluminescence resonance energy transfer, which demonstrates imaging of $\mathrm{O}_{2}{ }^{--}$at the picomolar level in mice. ${ }^{17}$ However, because of the deficiency of reversibility, the PCLA- ${ }_{2}{ }^{--}$was not able to dynamically image $\mathrm{O}_{2}{ }^{-}$. Therefore, in order to directly uncover the linkage between the $\mathrm{O}_{2}{ }^{--}$level and acute exercise or emotional changes, ideal fluorescence imaging probes for real-time visualization of $\mathrm{O}_{2}{ }^{-}$levels in vivo are still scarce.

Currently, CDs have attracted extensive interest owing to their good biocompatibility, excellent two-photon properties, optical stability and slow diffusion. CD-based nanosensors have been used for sensing $\mathrm{pH}$, metal ions, $\mathrm{H}_{2} \mathrm{~S}$, and so forth. ${ }^{18-23}$ To construct CD-based nanosensors, the procedure of engineering CD surfaces with diverse functions is generally complicated. 
Therefore, improved methods for building a CD-based nanosensor are still highly demanded. In previous studies, Te and Se have been successfully confirmed as active sites to mimetic glutathione peroxidase. ${ }^{24}$ These properties of Te and Se inspired researchers to design a series of Te- and Se-containing probes that can be applied for dynamic and reversible imaging of active small molecules such as ROS and mercaptan in cells. ${ }^{25-33}$ Considering that the recognition ability of Se- and Te-based active sites is mainly focused on ROS, in order to realize the dynamic fluorescence imaging of native $\mathrm{O}_{2}{ }^{--}$fluctuation during intensive exercise or acute emotional changes, the introduction of Se- and Te-based active sites into CD-based nanosensors may offer a useful perspective on $\mathrm{O}_{2}{ }^{--}$recognition.

Based on the above strategies, we developed three $\mathrm{O}_{2}{ }^{\cdot-}$ fluorescent probes (FO-PTe, Te-CDs and Se-CDs) (Scheme 1 and Fig. S1†). Among them, the Te-containing molecular probe (FOPTe) with 9-fluorenone as a fluorophore was covalently linked with two Te-containing moieties, which could achieve dynamic and reversible detection of $\mathrm{O}_{2}{ }^{--}$through the redox properties of the Te-center. Two other kinds of Se- and Te-containing CD were prepared from Te- and Se-containing molecular probes (FO-PTe and FO-PSe) as the carbon source, respectively. The observed results demonstrated that all three probes had good selectivity for $\mathrm{O}_{2}{ }^{-}$. More importantly, the Te-CDs and Se-CDs exhibited excellent reversibility and an instantaneous response. Their reversibility was attributed to the redox of the Te- or Se-center by further characterization. In particular, the detection limit of TeCDs reached $8.0 \mathrm{pM}$. These probes were applied in live cells and tumor tissues to image $\mathrm{O}_{2}{ }^{\cdot-}$. The results indicated that the TeCDs exhibited the highest sensitivity to track the endogenous $\mathrm{O}_{2}{ }^{\cdot-}$ level without external stimulation. Through two-photon fluorescence imaging, we found that the $\mathrm{O}_{2}{ }^{--}$level

(a)
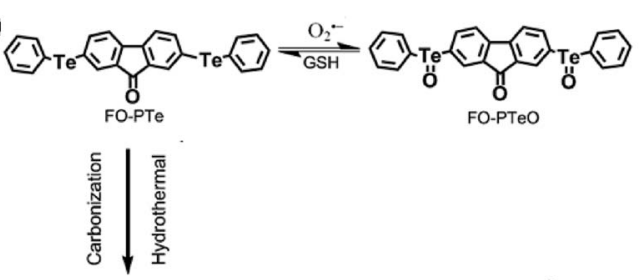

(b)

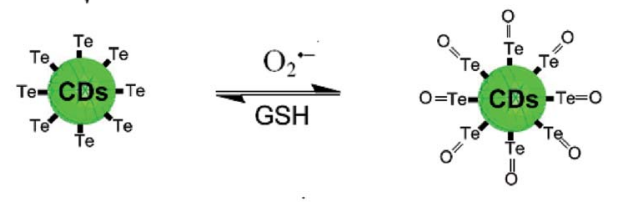

(c)

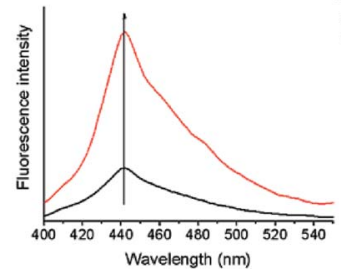

(d)

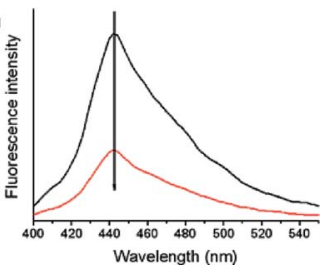

Scheme 1 (a) Proposed reaction mechanism and structures of the molecular probes FO-PTe and its oxidized product FO-PTeO; (b) proposed reaction mechanism of $\mathrm{Te}-\mathrm{CD}$ and its oxidized product $\mathrm{TeO}-\mathrm{CD}$; (c) fluorescence enhancement of the Te-CDs with $\mathrm{O}_{2}{ }^{\cdot-}$; (d) fluorescence response of the TeO-CDs with GSH.
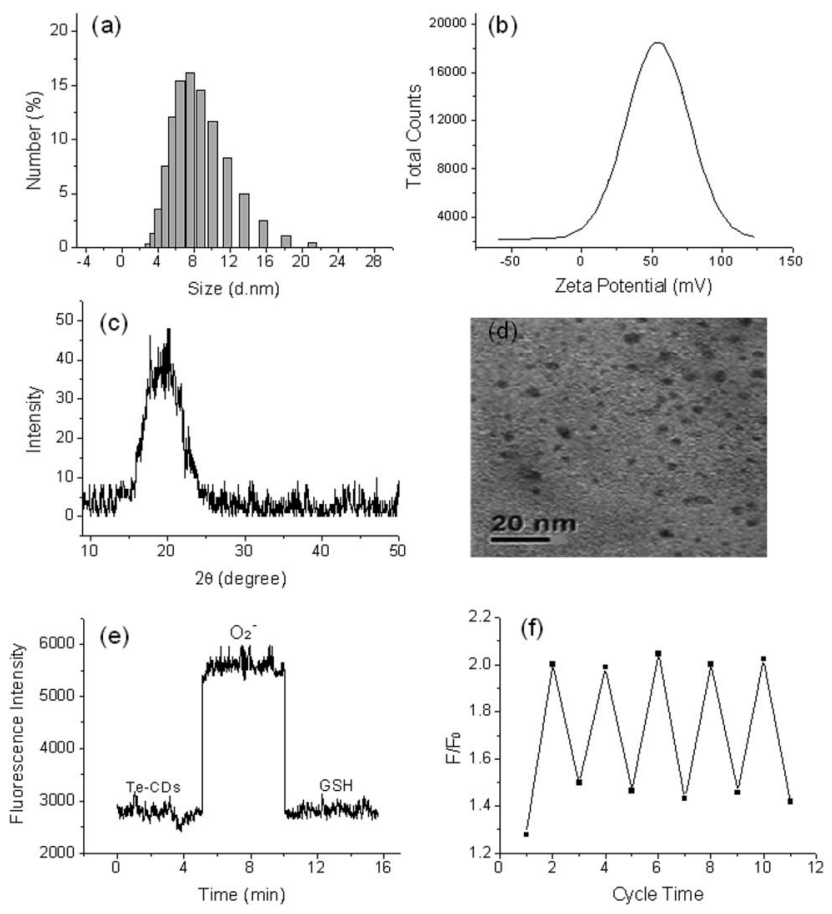

Fig. 1 (a) Characterization of the Te-CDs by DLS images, (b) the zeta potential, (c) XRD analysis, (d) the TEM images, and (e) time course of Te-CDs $\left(5.0 \mu \mathrm{g} \mathrm{ml}^{-1}\right.$ ) as measured by a spectrofluorometer. The TeCDs were oxidized by 1 equiv. of added $\mathrm{O}_{2}{ }^{\cdot-}$, after which the solution was treated with 2 equiv. of GSH; (f) fluorescence redox cycle responses of Te-CDs. The Te-CDs were oxidized by 1 equiv. of added $\mathrm{O}_{2}{ }^{--}$, after which the solution was treated with 2 equiv. of $\mathrm{GSH}$.
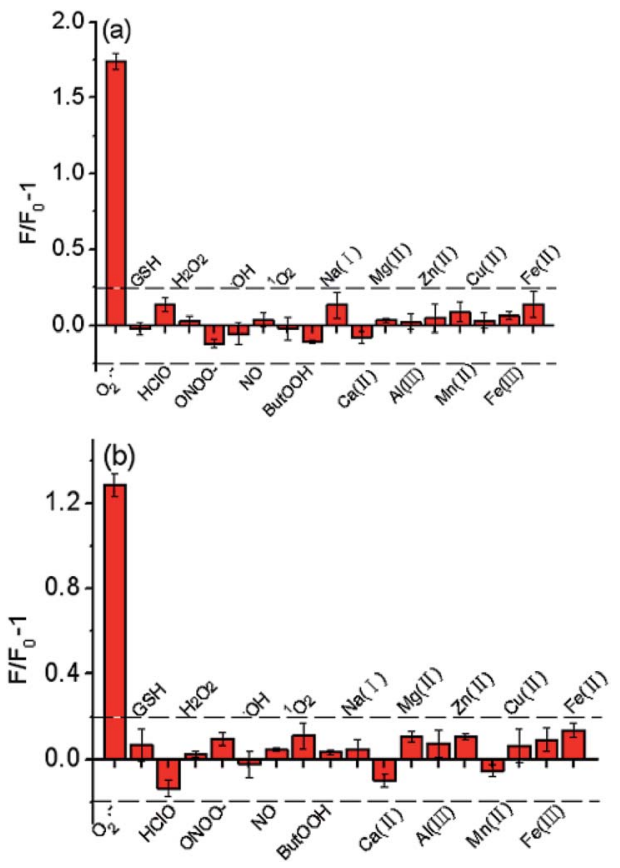

Fig. 2 (a) Fluorescence responses of Te-CDs $\left(5.0 \mu \mathrm{g} \mathrm{ml}^{-1}\right)$ to different ROS and metal ions. The concentrations of other ROS and metal ions were $10 \mu \mathrm{M}$. (b) Fluorescence responses of FO-PTe $(10 \mu \mathrm{M})$ to different active species. The concentrations of other active species were $10 \mu \mathrm{M}$. 

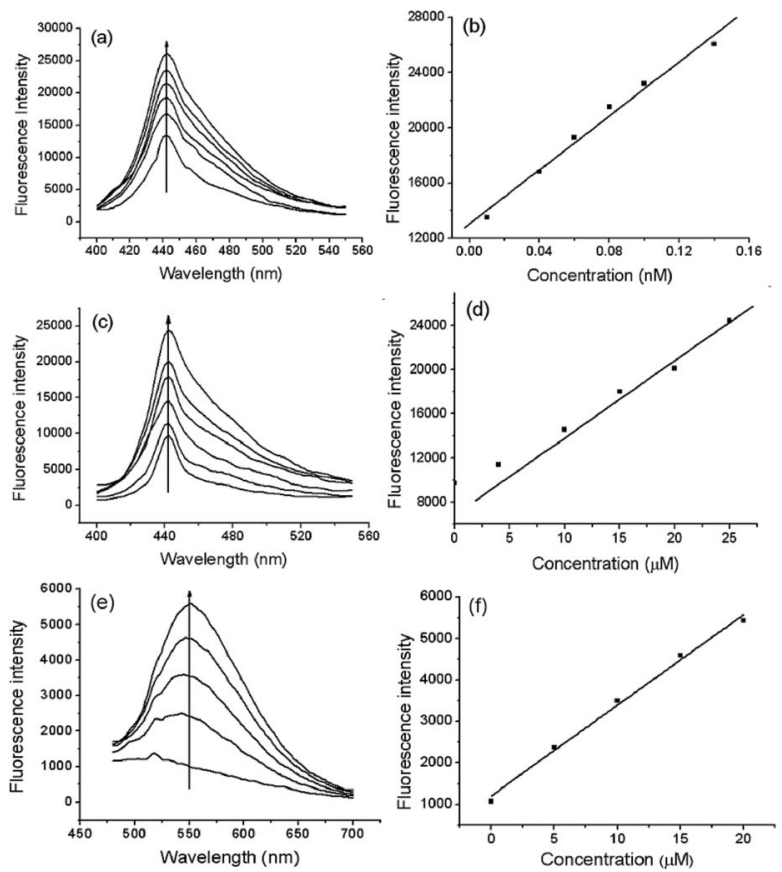

Fig. 3 Sensitivity of the probes. (a) Fluorescence response of Te-CDs $\left(5.0 \mu \mathrm{g} \mathrm{ml}^{-1}\right)$ after adding various concentrations of $\mathrm{O}_{2}{ }^{\cdot-}$ in Tris $(0.015$ M) solution $\mathrm{pH} 7.4$, (b) a linear correlation between the fluorescence intensity and $\mathrm{O}_{2} \cdot{ }^{\cdot-}$ concentrations, (c) fluorescence response of $\mathrm{FO}$ PTe $(10.0 \mu \mathrm{M})$ after adding various concentrations of $\mathrm{O}_{2}{ }^{--}$in Tris $(0.015$ M) solution (DMSO/water $=1: 9 \mathrm{v} / \mathrm{v}, \mathrm{pH} 7.4$ ), (d) a linear correlation between the fluorescence intensity and $\mathrm{O}_{2}{ }^{--}$concentrations, (e) fluorescence spectra of Se-CDs $\left(10.0 \mu \mathrm{g} \mathrm{m}^{-1}\right)$ after adding various concentrations of $\mathrm{O}_{2}{ }^{\cdot-}$ and (f) a linear correlation between the fluorescence intensity and $\mathrm{O}_{2}{ }^{\cdot-}$ concentrations.

significantly increased in mice during acute strenuous exercise and emotional changes. Finally, we explored the $\mathrm{O}_{2}{ }^{--}$levels in the brains of the depressive mice using Te-CDs, which instantaneously and dynamically indicated the changes in $\mathrm{O}_{2}{ }^{--}$ concentration.

\section{Results and discussion}

\section{Reaction mechanism, characterization and spectral properties of the probes}

Three fluorescent probes were constructed and the structure, reaction mechanism and spectral properties are shown in Scheme 1 and Fig. S1. $\dagger$ The Te-based active site with 9-fluorenone as the fluorophore was employed to fabricate the reversible organic molecular fluorescent probe FO-PTe. After reaction with $\mathrm{O}_{2}{ }^{\cdot-}$, the fluorescence intensity of FO-PTe enhanced, and the resultant product was FO-PTeO. When FOPTeO underwent a reaction with glutathione (GSH), its fluorescence intensity became quenched. Thus, the reversible and dynamic response of $\mathrm{O}_{2}{ }^{--}$might be realized through the redox of the Te-based active site in FO-PTe. Using FO-PTe as the carbon source, the functional Te-CDs were prepared by a single hydrothermal reaction step. The fluorescence intensity of the Te-CDs $\left(\lambda_{\text {ex }}, 380 \mathrm{~nm} ; \lambda_{\mathrm{em}}, 440 \mathrm{~nm}\right)$ increased after reaction with

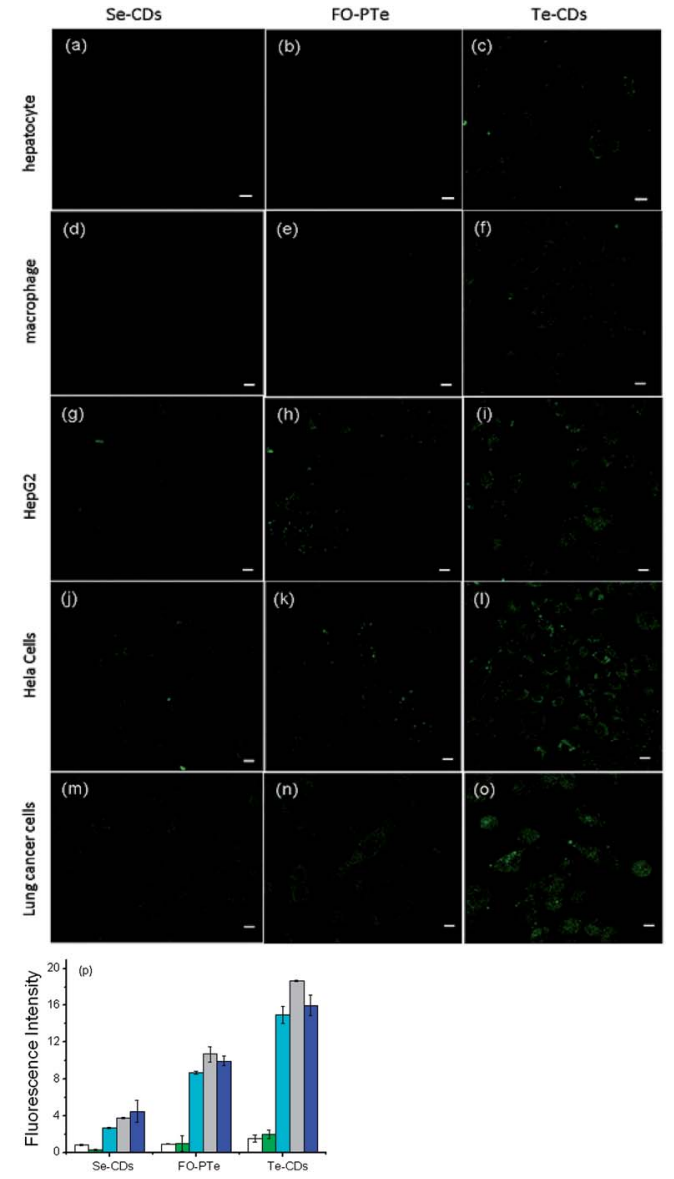

Fig. 4 Two-photon imaging analysis of $\mathrm{O}_{2}{ }^{--}$in cells. (a), (b) and (c) imaging of $\mathrm{O}_{2} \cdot{ }^{--}$in hepatocyte cells by Se-CDs, FO-PTe, and Te-CDs, respectively, (d), (e) and (f) imaging of $\mathrm{O}_{2}{ }^{--}$in macrophage cells by SeCDs, FO-PTe, and Te-CDs, respectively, (g), (h) and (i) imaging of $\mathrm{O}_{2}{ }^{\cdot-}$ in HepG 2 cells by Se-CDs, FO-PTe, and Te-CDs, respectively, (j), (k) and (l) imaging of $\mathrm{O}_{2}{ }^{--}$in Hela cells by Se-CDs, FO-PTe, and Te-CDs, respectively, (m), (n) and (o) imaging of $\mathrm{O}_{2}{ }^{--}$in lung cancer cells by SeCDs, FO-PTe, and Te-CDs, respectively and (p) the data output of fluorescence images. White: hepatocyte; green: macrophage; light blue: HepG2; gray: HeLa cells; dark blue: lung cancer cells. The concentration of the Te-CDs and Se-CDs was $5.0 \mu \mathrm{g} \mathrm{ml}^{-1}$ and $10.0 \mu \mathrm{g}$ $\mathrm{ml}^{-1}$, respectively. The scale bar is $5 \mu \mathrm{m}$. Two-photon images were acquired using $800 \mathrm{~nm}$ excitation and two-photon fluorescence emission windows: $400-500 \mathrm{~nm}$ for FO-PTe and Te-CDs and 500$600 \mathrm{~nm}$ for Se-CDs.

$\mathrm{O}_{2}{ }^{--}$(Scheme 1c), and the obtained product is TeO-CD. After reaction with GSH, the fluorescence of TeO-CDs decreased and the product is Te-CD (Scheme 1d). Through redox cycling between $\mathrm{Te}$ and $\mathrm{Te}=\mathrm{O}$ (Scheme $1 \mathrm{~b}$ ), the probe has the ability to dynamically sense $\mathrm{O}_{2}{ }^{-}$. In order to further study the reaction mechanism and the analytical properties of the Te-CDs, we prepared Se-CDs using the molecular probe FO-PSe as a carbon source. ${ }^{34-36}$ The fluorescence response of Se-CDs $\left(\lambda_{\mathrm{ex}}, 440 \mathrm{~nm}\right.$ and $\lambda_{\mathrm{em}}, 550 \mathrm{~nm}$ ) with $\mathrm{O}_{2}{ }^{-}{ }^{-} / \mathrm{GSH}$ was also investigated (Fig. S1c and $\mathrm{d} \dagger$ ). According to further characterization, we found that the structure of the directly obtained CDs was SeO-CD using the molecular probe FO-PSe as the carbon source, and then Se-CDs were produced after treatment with GSH. These results 

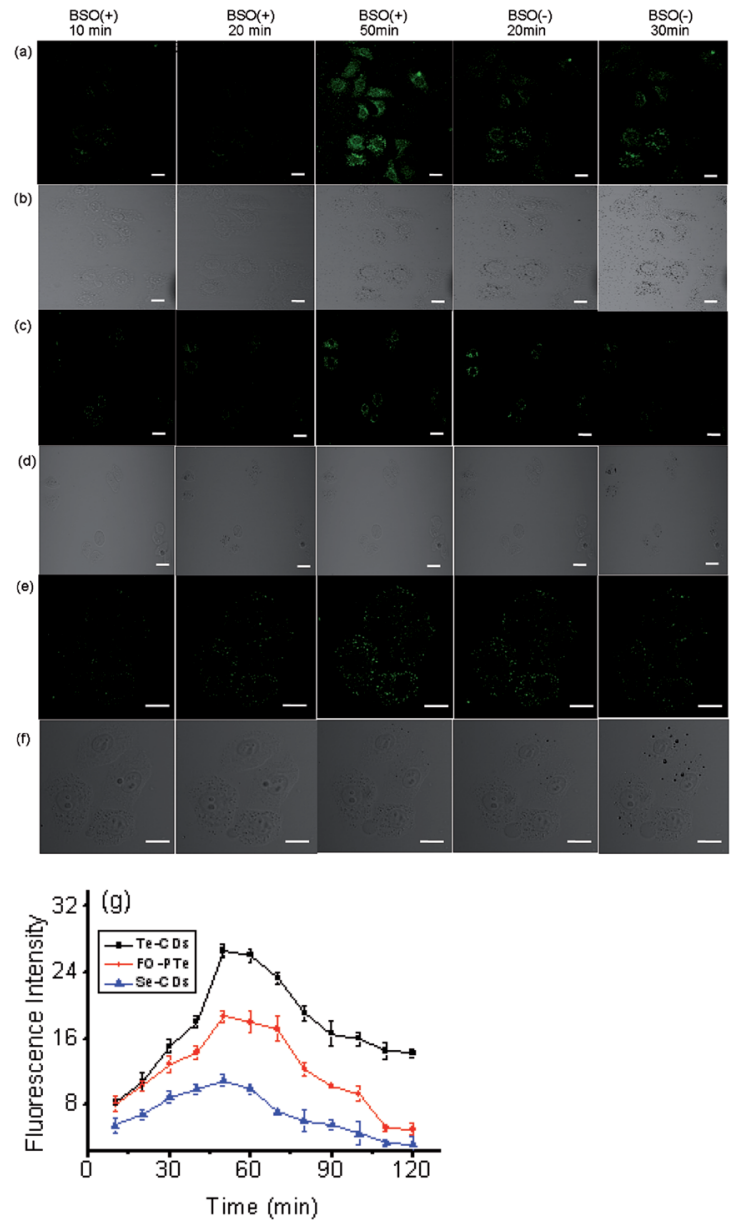

Fig. 5 Two-photon fluorescence imaging of $\mathrm{O}_{2}{ }^{\cdot-}$ in the process of BSO-induced hepatocyte apoptosis with ( $a$ and b) Te-CDs, (c and d) FO-PTe and (e and f) Se-CDs. The CD-loaded hepatocyte cells were treated with $5.0 \mathrm{mM} \mathrm{BSO}$. BSO was then removed, and the HL-7702 cells were further cultured in a fresh cell medium. (g) The data output of the fluorescence images. The concentration of the Te-CDs and SeCDs was $5.0 \mu \mathrm{g} \mathrm{ml}^{-1}$ and $10.0 \mu \mathrm{g} \mathrm{ml}^{-1}$, respectively. The scale bar is 10 $\mu \mathrm{m}$. Two-photon images were acquired using $800 \mathrm{~nm}$ excitation, twophoton fluorescence emission windows: 400-500 nm for FO-PTe and Te-CDs and 500-600 nm for Se-CDs

suggested that the reversible response to $\mathrm{O}_{2}{ }^{\cdot-}$ might also be realized by redox cycling of the Se-based active site. In addition, the corresponding structure and the recognition mechanism of the two CDs were well characterized by TEM, DSL, XRD, Zpotential, XPS and Te and Se NMR (Fig. 1a-d, S2-S7†).

\section{Reversibility of the probes}

To determine whether the probes have reversible recognition ability, $\mathrm{O}_{2}{ }^{-}-\mathrm{GSH}$ was used to further test their fluorescence response over time. The fluorescence intensity of the Te-CDs significantly enhanced after the reaction with $\mathrm{O}_{2}{ }^{--}$(Fig. 1e). In the meantime, the fluorescence intensity decreased rapidly when reacted with GSH, which indicated the good reversibility and instantaneity of the probe. Then the reversibility of the probe was further characterized through multiple redox cycling experiments with $\mathrm{O}_{2}{ }^{-}-$GSH (Fig. 1f). The same experiment was
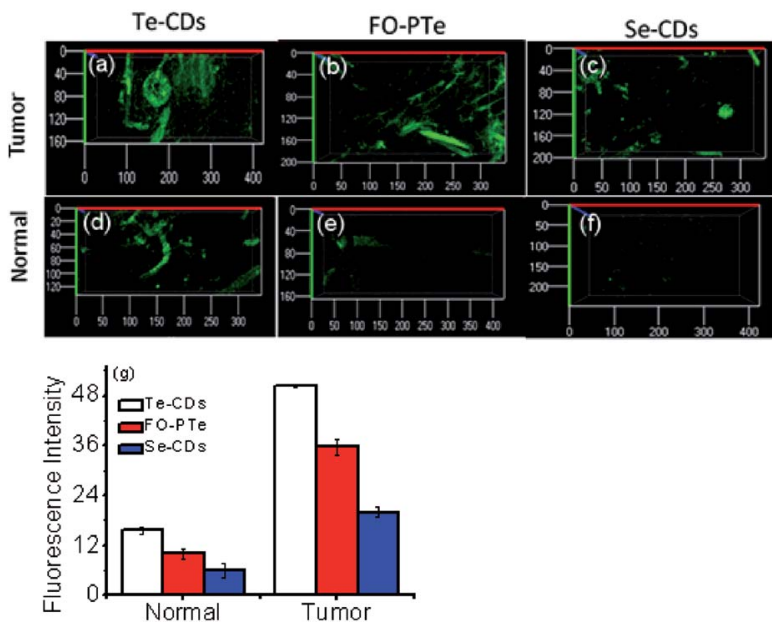

Fig. 6 Fluorescence imaging of $\mathrm{O}_{2}{ }^{-}$levels in the tumor tissues of mice with (a) Te-CDs, (b) FO-PTe and (c) Se-CDs and fluorescence imaging of $\mathrm{O}_{2}{ }^{--}$levels in the normal tissues of mice with (d) Te-CDs, (e) FO-PTe and (f) Se-CDs. (g) The data output of fluorescence imaging. The error bars were calculated from three parallel experiments. The concentration of the Te-CDs and Se-CDs was $5.0 \mu \mathrm{g} \mathrm{ml}^{-1}$ and $10.0 \mu \mathrm{g} \mathrm{ml}^{-1}$, respectively. Images were acquired using $800 \mathrm{~nm}$ two-photon excitation, two-photon fluorescence emission windows: 400-500 nm for FO-PTe and Te-CDs and 500-600 nm for Se-CDs. Eighteen mice were used in the experiment and the error bars were from three parallel experiments.

performed to examine the reversibility of the molecular probes FO-PTe and Se-CDs with $\mathrm{O}_{2}{ }^{\cdot-} / \mathrm{GSH}$. The experimental results exhibited the fast reaction speed and good reversibility of FOPTe and Se-CDs (Fig. S8 and S9†). Therefore, these results demonstrate that the redox cycling of the Se- or Te-based active site makes the probes dynamically and reversibly trace $\mathrm{O}_{2}{ }^{-}$.

\section{Selectivity of the probes}

To verify the selectivity of the probes, we investigated their fluorescence response to a number of biologically relevant small molecule and metal ion solutions. The fluorescence intensity of Te-CDs enhanced obviously after addition of $\mathrm{O}_{2}{ }^{-}$(Fig. 2a), while there was little change in the fluorescence intensity in the presence of other reactive species, suggesting the great recognition ability of Te-CDs toward $\mathrm{O}_{2}{ }^{-}-$. Next we confirmed the good selectivity of the molecular probe FO-PTe (Fig. 2b). As for the Se-containing CDs, we found that the fluorescence of the newly prepared CDs was significantly quenched after reaction with reducing species such as GSH and vitamin $\mathrm{C}(\mathrm{Vc})$, and the fluorescence was largely unchanged when other species were added (Fig. S10a $\dagger$ ). After the newly prepared Se-containing CDs were treated with a reducing agent, the product fluoresced strongly when $\mathrm{O}_{2}{ }^{\cdot-}$ was added and there was low fluorescence in the presence of some other biological substances (Fig. S10b $\dagger$ ). This confirmed that the directly prepared Secontaining CDs were SeO-CDs. Meanwhile, the structure was Se-CD after treatment with the reducing agent GSH. Altogether, these results provide strong evidence that Se or Te as active sites give the probes outstanding selectivity for $\mathrm{O}_{2}{ }^{--}$. 

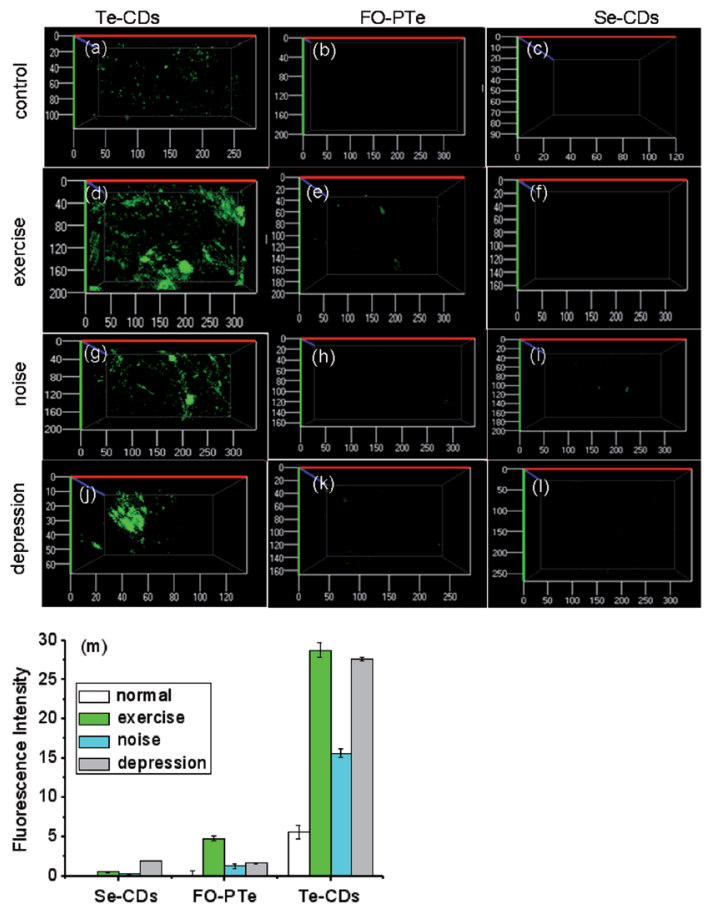

Fig. 7 Monitoring of $\mathrm{O}_{2}{ }^{-}-$levels in states of treadmill running, noise interference and depression in mice. (a), (b) and (c) 3D distribution of $\mathrm{O}_{2}{ }^{--}$in the normal tissues of mice (control experiment) by Te-CDs, FO-PTe and Se-CDs, respectively, (d), (e) and (f) 3D distribution of $\mathrm{O}_{2}{ }^{\cdot-}$ in the normal tissues of mice during treadmill running by Te-CDs, FOPTe and Se-CDs, respectively, (g), (h) and (i) 3D distribution of $\mathrm{O}_{2}{ }^{\cdot-}$ in normal tissues of mice during induced irritability by Te-CDs, FO-PTe and Se-CDs, respectively, (j), (k) and (l) 3D distribution of $\mathrm{O}_{2}{ }^{\cdot-}$ in normal tissues of mice under the condition of depression by Te-CDs, FO-PTe and Se-CDs, respectively, and $(\mathrm{m})$ the data output of fluorescence imaging. The concentration of the Te-CDs and Se-CDs was $5.0 \mu \mathrm{g} \mathrm{ml}^{-1}$ and $10.0 \mu \mathrm{g} \mathrm{ml}^{-1}$, respectively. The images were acquired using $800 \mathrm{~nm}$ two-photon excitation, two-photon fluorescence emission windows: $400-500 \mathrm{~nm}$ for FO-PTe and Te-CDs and 500$600 \mathrm{~nm}$ for Se-CDs. Thirty-six mice were used in the experiment and the error bars were from three parallel experiments.

\section{Sensitivity of the probes}

We compared the sensitivity of the probes. Fig. 3a shows that the fluorescence intensity of Te-CDs gradually enhanced as $\mathrm{O}_{2}{ }^{--}$ concentrations increased, and the linear relationship in the concentration range of $0.01-0.14 \mathrm{nM}$ had a correlation coefficient of 0.9934 . Notably, the detection limit reached $8.0 \mathrm{pM}(n=$ 11 and $\mathrm{S} / \mathrm{N}=3$ ), which is a record sensitivity. Fig. 3c shows the fluorescence response of the molecular probe FO-PTe with different concentrations of $\mathrm{O}_{2}{ }^{-}$, and the linear relationship in the concentration range of $4.0-25.0 \mu \mathrm{M}$ with a correlation coefficient and detection limit of 0.9912 and $0.15 \mu \mathrm{M}$, respectively ( $n=11$ and $\mathrm{S} / \mathrm{N}=3$ ). Next, the response of Se-CDs with $\mathrm{O}_{2}{ }^{-{ }^{-}}$was also investigated (Fig. 3e). The probe showed a linear relationship in the concentration range of 5.0-20.0 $\mu \mathrm{M}$, and the correlation coefficient and detection limit were 0.9989 and $0.12 \mu \mathrm{M}$, respectively ( $n=11$ and $\mathrm{S} / \mathrm{N}=3$ ). By comparison, Te-CDs exhibited ultra-high sensitivity, which is suitable for the imaging of $\mathrm{O}_{2}{ }^{--}$at native levels in cells and in vivo because the
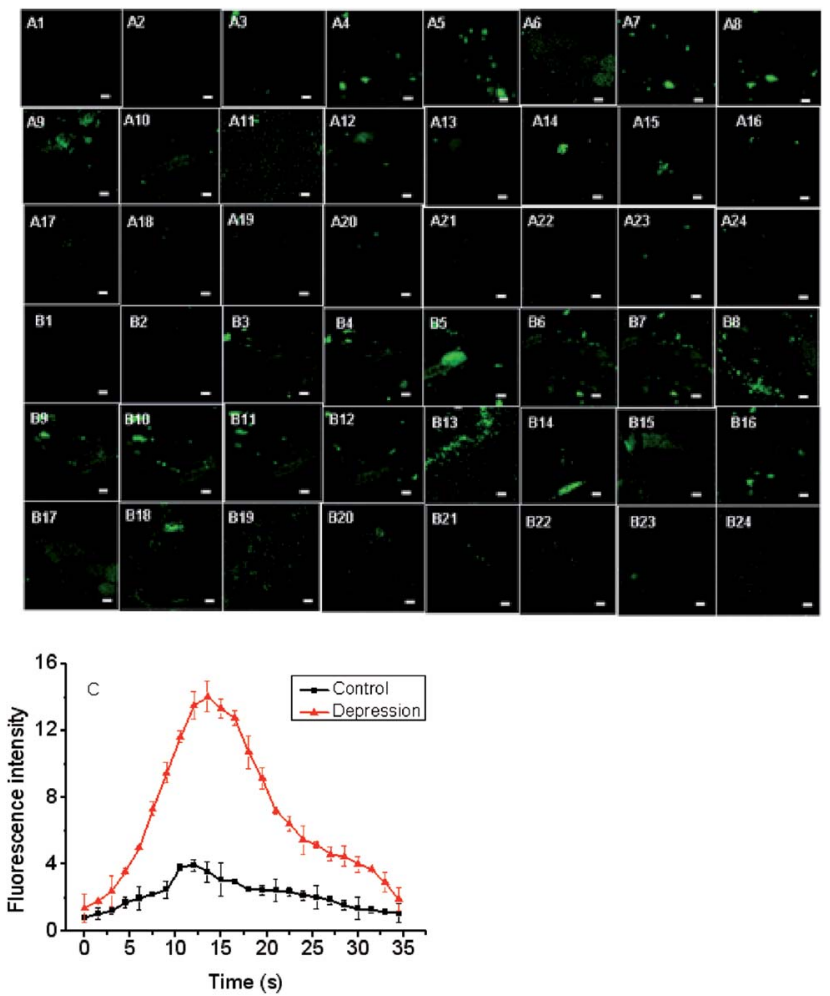

Fig. 8 Monitoring the $\mathrm{O}_{2}{ }^{--}$dynamic fluctuations in the brain of the depression model using Te-CDs. (A1-A24) The changes of $\mathrm{O}_{2}{ }^{\cdot-}$ dynamic fluctuations in the brain of mice, and each picture interval is 2 seconds, (B1-B24) the changes of $\mathrm{O}_{2}{ }^{--}$dynamic fluctuations in the brain of the depression model, and each picture interval is 2 seconds; (C) data output of fluorescence imaging. The concentration of the TeCDs and Se-CDs was $5.0 \mu \mathrm{g} \mathrm{ml}^{-1}$ and $10.0 \mu \mathrm{g} \mathrm{ml}^{-1}$, respectively. Images were acquired using $800 \mathrm{~nm}$ two-photon excitation, twophoton fluorescence emission windows: $400-500 \mathrm{~nm}$. The scale bar is $20 \mu \mathrm{m}$. Five mice were used in the experiment and the error bars were from five parallel experiments.

$\mathrm{O}_{2}{ }^{\cdot-}$ level is about $10^{-10} \mathrm{M}$ in biological systems. ${ }^{1}$ The reasons for the difference in detection limit may be as follows: (1) comparing the Te-CDs and the molecular probe FO-PTe, there is an obviously different luminescence mechanism between the CDs and the molecular probes, and a much larger two-photon absorption cross section of Te-CDs (9707 GM, ESI $\dagger$ ) heightening the sensitivity and (2) comparing the Se-CDs and Te-CDs, the difference of the Se- and Te-based CDs lies in the difference between Se and Te. According to the radius formula of quantum dots, the theoretical radius of Te-CDs is smaller than that of SeCDs. $^{34}$ Considering that the atomic radius of Te is larger than that of Se, and the specific surface area of a quantum dot increases sharply with the decrease in size, we suppose that the effective ratio of the Te-based active site in Te-CDs is higher than that of the Se-based active site in Se-CDs. The above reasons lead to the Te-CDs having the best sensitivity among these probes.

\section{Imaging analysis of $\mathrm{O}_{2}{ }^{--}$in live cells}

We next investigated how the three probes responded to $\mathrm{O}_{2}{ }^{--}$ inside different cells (hepatocyte, HepG2 cells, macrophages, 
Hela cells and lung cancer cells, Fig. 4). ${ }^{37,38}$ In two-photon fluorescence images, clearer fluorescence was observed within tumor cells than normal cells, indicating higher $\mathrm{O}_{2}{ }^{--}$concentrations than in normal cells. In particular, the Te-CDs (Fig. 4p) showed the brightest fluorescence, demonstrating a supersensitive imaging capability for $\mathrm{O}_{2}{ }^{--}$. These results manifest that the Te-CD probe possesses obvious advantages for tracking native $\mathrm{O}_{2}{ }^{-}$in cells without external stimulation.

To further test the performance of the probes for imaging $\mathrm{O}_{2}{ }^{\cdot-}$, three probes were used to monitor the changes in $\mathrm{O}_{2}{ }^{--}$ levels in hepatocytes during L-buthionine sulfoximine (BSO) induced apoptosis (Fig. 5). We observed that the fluorescence within these cells gradually elevated as time went on, which should be attributable to the rapid increase of $\mathrm{O}_{2}{ }^{--}$during the process of apoptosis. After removal of BSO, intracellular fluorescence brightness was obviously weakened. These results suggested that these probes could measure real-time dynamic changes in $\mathrm{O}_{2}{ }^{-}$concentrations due to their fluorescence response reversibility. Through comparing fluorescence images of the three probes, the Te-CDs also present the most distinct fluorescence, thereby proving to be equipped with fascinating characteristics for supersensitive and dynamic imaging. In addition, after addition of Tiron (superoxide scavenger), the fluorescence image brightness obviously weakened (Fig. S17 and $\mathrm{S} 18 \dagger$ ), which provides evidence that the changes in fluorescence were due to changes in $\mathrm{O}_{2}{ }^{\cdot-}$.

\section{Imaging analysis of $\mathrm{O}_{2}{ }^{--}$in tumor tissue of mice}

In order to examine the feasibility of the probes in living animals, they were applied to the normal abdomen tissue and breast tumor tissue of mice (Fig. 6). Apparently, much brighter fluorescence appeared in the tumor tissue than the normal tissue. This signified a pronouncedly higher $\mathrm{O}_{2}{ }^{-}-$level in the mouse tumor tissue. These imaging results suggested that the three probes were able to track $\mathrm{O}_{2}{ }^{-}$in small animals, combined with deep tissue penetration and reduced background fluorescence of two-photon microscopy. Significantly, the Te-CDs exhibited the best imaging quality with $\mathrm{O}_{2}{ }^{--}$, especially in the normal tissue. Moreover, the imaging depth reached more than $800 \mu \mathrm{m}$ (Fig. S19†). This phenomenon is due to the very high sensitivity, passive targeting and slow diffusion rate of the Te-CDs. From these results, we believe that the TeCDs have enough capability to implement the imaging of $\mathrm{O}_{2}{ }^{--}$ in vivo without an external stimulus.

\section{$\mathrm{O}_{2}{ }^{--}$fluctuations in mice under intense exercise conditions and emotional changes}

To explore how acute strenuous exercise and emotional changes influence $\mathrm{O}_{2}{ }^{\cdot-}$ levels in small animals, we constructed three mouse models including: intense exercise of $1.5 \mathrm{~h}$ treadmill running, induced irritability by noise interference and mild depression after forced swimming. ${ }^{39,40}$ The three probes (FOPTe, Te-CDs and Se-CDs) were then employed to observe $\mathrm{O}_{2}{ }^{--}$ concentrations in the abdomen of these mice (Fig. 7). Notably, the abdomen of the normal mice injected with Te-CDs displayed perceptible fluorescence (Fig. 7a), which was due to native $\mathrm{O}_{2}{ }^{-}$levels in the control group. Furthermore, stronger fluorescence was observed for the mice under acute exercise, irritability and depressive states (Fig. 7d, g, j and m), revealing the distinct rise in $\mathrm{O}_{2}{ }^{-}$concentrations. This means that the $\mathrm{O}_{2}{ }^{\cdot-}$ increase may lead to oxidative damage to organisms. Moreover, the superoxide scavenger (Tiron) was used to support the observed fluorescence that can be assigned to the presence and reactivity of $\mathrm{O}_{2}{ }^{--}$towards the probe. The fluorescence image brightness obviously weakened (Fig. S22†), suggesting that the changes in fluorescence were from the changes in $\mathrm{O}_{2}{ }^{\cdot-}$.

To further confirm the changes of $\mathrm{O}_{2}{ }^{--}$in the mild depression model, the Te-CD probe was applied in the brain for realtime imaging. We found that the fluorescence brightness increased gradually and then decreased gradually over time (Fig. 8), reflecting dynamic changes of the $\mathrm{O}_{2}{ }^{-}$levels in the brain of the depressed mouse (Fig. 8c). We speculated that the changes of $\mathrm{O}_{2} \cdot-$ during imaging were mainly due to "superoxide flashes", which involve the transient openings of mitochondrial permeability transition pore stimulating superoxide production by the electron transport chain. ${ }^{15}$ Compared with the control group, the concentration of $\mathrm{O}_{2}{ }^{--}$in the brain of the depressed mice increased significantly. These results suggest a close relationship between ROS and depression.

\section{Conclusions}

For research on health or disease, the relationship between the $\mathrm{O}_{2}{ }^{-}-$level and acute exercise and emotional changes was revealed using three probes, including Te-CDs, FO-PTe and SeCDs, which were developed for monitoring intrinsic levels of $\mathrm{O}_{2}{ }^{--}$based on the $\mathrm{Se}$ or Te active sites. These probes can instantaneously and dynamically respond to $\mathrm{O}_{2}{ }^{--}$with specific recognition. Interestingly, Te-CDs displayed the highest and a record sensitivity with the detection limit at a picomolar level. Application of the three probes in different cells and tissues by two-photon fluorescence imaging confirmed that the Te-CDs were the most suitable for tracking $\mathrm{O}_{2}{ }^{-}$fluctuation without external stimulation. Mouse abdomen imaging using Te-CD, uncovered that the level of $\mathrm{O}_{2}{ }^{--}$increased sharply under intense exercise, irritability and mild depression. Furthermore, dynamic imaging in the brain of the mild depression model revealed $\mathrm{O}_{2}{ }^{--}$at a higher level. This work provides a new strategy and ideal imaging tool to unravel the influence of acute exercise and emotional change on health from the ROS level.

\section{Conflicts of interest}

There are no conflicts to declare.

\section{Acknowledgements}

This work was supported by National Natural Science Foundation of China (21390411, 21535004 and 21305080). The Primary Research Plan of Shandong Province (2017GSF18196). Natural Science Foundation of Shandong Province (ZR2015JL008). 


\section{Notes and references}

1 M. P. Murphy, A. Holmgren, N. G. Larsson, B. Halliwell, C. J. Chang, B. Kalyanaraman, S. G. Rhee, P. J. Thornalley, L. Partridge, D. Gems, T. Nyström, V. Belousov, P. T. Schumacker and C. C. Winterbourn, Cell Metab., 2011, 13, 361-366.

2 D. R. Green, L. Galluzzi and G. Kroemer, Science, 2011, 333, 1109-1112.

3 F. He, J. Li, Z. Liu, C. C. Chuang, W. Yang and L. Zuo, Front. Physiol., 2016, 7, 486.

4 M. Viikki, S. Anttila, O. Kampman, A. Illi, M. Huuhka, E. Setälä-Soikkeli, N. Mononen, T. Lehtimäki and E. Leinonen, Neurosci. Lett., 2010, 477, 105-108.

5 J. M. Encinas, A. Vaahtokari and G. Enikolopov, Proc. Natl. Acad. Sci. U. S. A., 2006, 103, 8233-8238.

6 M. Bilici, H. Efe, M. A. Koroglu, H. A. Uydu, M. Bekaroglu and O. Deger, J. Affective Disord., 2001, 64, 43-51.

7 M. Schieber and N. S. Chandel, Curr. Biol., 2014, 24, R453R462.

8 M. Valkoa, D. Leibfritz, J. Moncol, M. T. D. Cronin, M. Mazur and J. Telser, Int. J. Biochem. Cell Biol., 2007, 39, 44-84.

9 F. Esposito, R. Ammendola, R. Faraonio, T. Russo and F. Cimino, Neurochem. Res., 2004, 29, 617-628.

10 D. J. Stephens and V. J. Allan, Science, 2003, 300, 82-86.

11 J. H. Lee, C. S. Lim, Y. S. Tian, J. H. Han and B. R. Cho, J. Am. Chem. Soc., 2010, 132, 1216-1217.

12 J. Chan, S. C. Dodani and C. J. Chang, Nat. Chem., 2012, 4, 973-984.

13 X. Li, X. Gao, W. Shi and H. Ma, Chem. Rev., 2014, 114, 590659.

14 B. C. Dickinson and C. J. Chang, Nat. Chem. Biol., 2011, 7, 504-511.

15 W. Wang, H. Fang, L. Groom, A. Cheng, W. Zhang, J. Liu, X. Wang, K. Li, P. Han, M. Zheng, J. Yin, W. Wang, M. P. Mattson, J. P. Y. Kao, E. G. Lakatta, S. S. Sheu, K. Ouyang, J. Chen, R. T. Dirksen and H. Cheng, Cell, 2008, 134, 279-290.

16 W. Zhang, P. Li, F. Yang, X. Hu, C. Sun, W. Zhang and D. Chen, J. Am. Chem. Soc., 2013, 135, 14956-14959.

17 P. Li, L. Liu, H. Xiao, W. Zhang, L. Wang and B. Tang, J. Am. Chem. Soc., 2016, 138, 2893-2896.

18 P. C. Hsu and H. T. Chang, Chem. Commun., 2012, 48, 39843986.
19 S. N. Baker and G. A. Baker, Angew. Chem., Int. Ed., 2010, 49, 6726-6744.

20 J. Ge, Q. Jia, W. Liu, L. Guo, Q. Liu, M. Lan, H. Zhang, X. Meng and P. Wang, Adv. Mater., 2015, 27, 4169-4177.

21 L. Pan, S. Sun, A. Zhang, K. Jiang, L. Zhang, C. Dong, Q. Huang, A. Wu and H. Lin, Adv. Mater., 2015, 27, 77827787.

22 C. Ding, A. Zhu and Y. Tian, Acc. Chem. Res., 2014, 47, 20-30.

23 J. Liu, Y. Liu, N. Liu, Y. Han, X. Zhang, H. Huang, Y. Lifshitz, S. T. Lee, J. Zhong and Z. Kang, Science, 2015, 347, 970-974.

24 S. T. Manjare, Y. Kim and D. G. Churchill, Acc. Chem. Res., 2014, 47, 2985-2998.

25 F. Yu, P. Li, B. Wang and K. Han, J. Am. Chem. Soc., 2013, 135, 7674-7680.

26 F. Yu, P. Li, G. Li, G. Zhao, T. Chu and K. Han, J. Am. Chem. Soc., 2011, 133, 11030-11033.

27 B. Tang, Y. Xing, P. Li, N. Zhang, F. Yu and G. Yang, J. Am. Chem. Soc., 2007, 129, 11666-11667.

28 K. Xu, M. Qiang, W. Gao, R. Su, N. Li, Y. Gao, Y. Xie, F. Kong and B. Tang, Chem. Sci., 2013, 4, 1079-1086.

29 S. Wang, N. Li, W. Pan and B. Tang, TrAC, Trends Anal. Chem., 2012, 39, 3-37.

30 W. Liu, X. Li, Y. S. Wong, W. Zheng, Y. Zhang, W. Cao and T. Chen, ACS Nano, 2012, 6, 6578-6591.

31 S. T. Manjare, S. Kim, W. D. Heo and D. G. Churchill, Org. Lett., 2014, 16, 410-412.

32 K. Xu, Y. Zhang, B. Tang, J. Laskin, P. J. Roach and H. Chen, Anal. Chem., 2010, 82, 6926-6932.

33 M. R. Detty, P. B. Merkel, R. Hilf, S. L. Gibson and S. K. Powers, J. Med. Chem., 1990, 33, 1108-1116.

34 B. Han, J. Yuan and E. Wang, Anal. Chem., 2009, 81, 55695573.

35 W. Zhang, W. Liu, P. Li, J. Kang, J. Wang, H. Wang and B. Tang, Chem. Commun., 2015, 51, 10150-10153.

36 V. Georgakilas, J. A. Perman, J. Tucek and R. Zboril, Chem. Rev., 2015, 115, 4744-4822.

37 R. Liu, L. Zhang, X. Lan, L. Li, T. T. Zhang, J. H. Sun and G. H. Du, Neuroscience, 2011, 10, 408-419.

38 S. Thiberge, S. Blazquez, P. Baldacci, O. Renaud, S. Shorte, R. Ménard and R. Amino, Nat.Protoc., 2007, 2, 1811-1818.

39 R. D. Porsolt, L. M. Pichon and M. L. Jalfre, Nature, 1977, 266, 730-732.

40 H. Takeda, M. Tsuji, M. Inazu, T. Egashira and T. Matsumiya, Eur. J. Pharmacol., 2002, 449, 261-267. 